\title{
Politicians Talk
}

Weeks before the the federal election was called Refuge contacted three political figures who have subsequently been returned to Parliament, Minister of Employment and Immigration Barbara McDougall, Opposition Critic on Immigration and Multiculturalism Sergio Marchi, and NDP Critic on Immigration Dan Heap, to question them about their refugee agendas. Eventually all three found time amid some frantic canvassing to grant us brief but revealing interviews, which are printed below in the order in which they occurred.

\section{Sergio Marchi}

\begin{abstract}
Alex Zisman: What are your reactions to Bills C-84 and C-55?

Sergio Marchi: We took great objections with both bills on a number of key areas. Firstly we had a lot of concerns with the pre-screening. They set up a Refugee Board and then they put a wall around it. If you are going to have a

"safe" means. They never defined what is going to go into that equation of deciding those countries, because you are going to get into much larger geopolitical issues and questions of international politics being played rather that the case of individual refugees. So we said do away with the "safe country" concept.
\end{abstract} Refugee Board that is going to give oral hearings, then you don't have to have a barrier to bar access of people getting to that boand. So we are saying drop the prescreening stage, allow people to make one oral effective and fair hearing and then make a determination. You can't ask a person at the border to say, "look, just give a bit of your story so I can figure out if you deserve a second hearing". If you are a legitimate refugee you are not only going to give a bit of your story, you would want to give all of your story, so not only is it unfair if you pre-screen, but it is also going to be ineffective because in large part you are going to have two oral hearings rather than one oral hearing in front of the proper authorities. So we said eliminate the pre-screening, because what the Tories were doing was simply trying to make the system more effective by minimizing the number of people getting into the system.

The second aspect was the "safe country". We feel that the "safe country" was another instrument that complemented the pre-screening so that the government could clean their hands of refugees going into the system. They said that the government is going to get a list of so called "safe countries". They never defined what

\section{They set up a Refugee Board and then they put a wall around it.}

Third, we felt that the system is as strong as your appeal system. When you are deciding cases of life or death you need a second appeal system that is going to try to catch people who, for whatever reason, have been rejected, who in fact need refuge.

If we can amend the bill in those areas without gutting it, we will do so. If, in fact, by doing that we just tear it all apart, then we will simply re-introduce our own bill very quickly, speed its passage through the House and get the system going.
On Bill C-84 we have objected to the fines and imprisonments of groups and churches and nuns and priests who may help a person come in without a valid visa only to be thrown in prison or face a fine. We find it as repugnant as anything we have ever seen in the last four years of government legislation. Chances are that a legitimate refugee won't have a valid document, because a true refugee doesn't wait to go to an office or an embassy; they run, they catch the first train, plane, bus or ship. The false refugees are counselled, and they probably get forged documents and so on. So, if you understand the true refugee reality, you shouldn't make the operating word the valid document. If a priest or a group counsels fraudulent claims knowingly, then we can stop that and publish that, and the groups told us that they would be prepared to do that. But to have legislation that would fine or imprison people based on helping someone who may not have a valid travelling document is obviously obscene and that would have no place in a Liberal legislation.

The second aspect, of turning back boats, again is a repeat of history, like the 1939 with the St. Louis. We feel in 1988 that that kind of clause has no place in the books and statutes of this country, that when they say that will deter smuggling. we say nonsense to that. We say bring the boat in, if it's a boat - then, they only look at boats, but most people come in by planes - if we look at boats we are saying bring the boat in, you have to see who is on board. Are there children? Women? 
Are they sick? Are they elderly? Do they have food? Do they have water? How can the Tories turn a boat around like that? So we bring it in, we look who is on board, we do processing, if there are illegitimate refugees then they will have to leave, and when we have the boat in harbour, in port, if there was a case were the captain abused, misused, was doing it for human profit, then we would impound that boat, fine and possibly imprison the captain. And we feel that would be a detriment, that would send a message. But, by simply turning the boat around, the worst that could happen is that the captain, with his money in his pocket, will only dump his passengers a bit further out or bring them somewhere else, and that won't discourage another captain, because they have nothing to lose. But if they lose their boat and they lose their freedom behind bars then they might think twice. So we are going to move on those pieces, and C-84 will obviously be gutted once we remove those parts.

AZ: If you suddenly allow eoery refugee claimant to have a hearing, there would be an even larger backlog. How do you plan to cope in a practical way with this problem?

SM: The pre-screening stage, though, from a practical view point is still timeconsuming. I mean the immigration adjudicators, the two officers at the border will still have to schedule an appointment, an interview to go over the pre-screening. So what I am saying is the government is setting up a pre-screening stage which will mean that you will have to talk and see, and those people have to provide some evidence so that you can say no or yes, move to stage two or leave. So that is still going to take time, that is still going to take talking. Then you got the Refugee Board, which is a second hearing all on its own. I say, if we have made a determination that at least we have to give a fair hearing, an ear to these people, then I am saying, "do it once, do it right and do it quickly, and give the message to refugee applicants that this is no monkey business, that we have got competent people who are going to be doing those interviews, and that at the first smell of illegitimacy that's it." And I believe that that would expedite the case, rather than going through a two-pronged approach, pre-screening once and then oral hearing. Applicant has a thing, pum, make an appointment, you make your hearing, quick turn around.

On the backlog situation - in 1984 the backlog was about 9,500 because we were

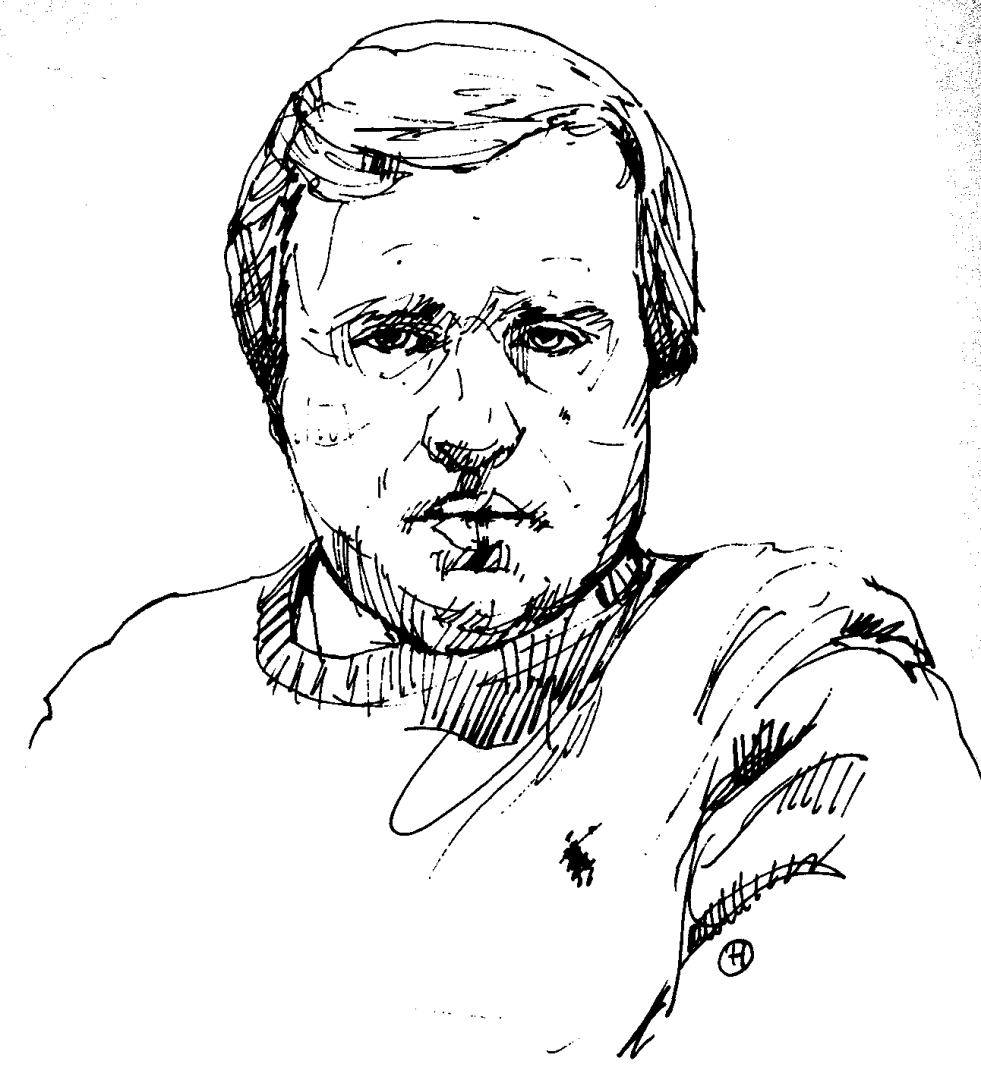

Sergio Marchi: "To ... fine or imprison people based on helping someone who may not have a valid travelling document is obviously obscene ..."

in transition from going to camps and picking people in the sixties and seventies to the reality of the eighties, people coming ashore. We didn't have the mechanisms, so it was growing. That's why we appointed Rabbi Plaut. It went from about $9,500-10,000$ in 1984 to 65,000 today. Barbara McDougall has not done a darned thing. First, she kept screaming at us saying, "I need the two bills to cure the problem". Now she's got those two bills and she is sitting on her political behind because she doesn't have the guts to do it during the campaign. And I am saying you are aggravating the problem by doing nothing.

There's three options. You do nothing, as they are doing. We are against that. You declare amnesty, and I am against that because that does not distinguish between right or wrong and it hurts the legitimate in favour of the illegitimate. So I am saying amnesty is as unfair as closed doors because there is no order. Then there is the compromise. What is that compromise? It is some sort of an administrative review where you set up a criteria: does he or she have family? Does he or she have job prospects? Does he or she possess language skills? Employment skills? Does he or she have relatives in the country? Some kind of criteria where you would judge the person's ability to integrate into this country and at the same time you would have the ability to reject people based on security, health or other risks for this country. So, it seems to me, that that is the way to go now. Not waiting, but now, so that if you have a new system it's not going to be paralyzed by immediately feeding it 65,000 people, 65,000 claims, because obviously that would paralyze the system. Then you would get Canadians saying, "well what the hell is going on. First you say there is a problem. Then you put up a new system and now it still breaks down." So if we are worried about the confidence of Canadians which will allow governments to be progressive, if you get backlashes, 
governments won't be progressive. If you have confidence, then governments can, in partnership with people, move in a right direction. So I am saying, yes let's get a new system, but this backlog has the potential of eating up that new system. And we've got to deal with both at the same time.

AZ: Are you categorically rejecting the "safe country" notion or are you also considering a rewording of that?

SM: I am saying that the Tories haven't produced what they would deem to be a "safe country". At the eleventh hour we even said: look, if you want the "safe country" concept, if you really believe in it, then allow the refugee groups and the immigrant groups, together with others, to define what is safe and not safe. Don't have the highest political body, the Cabinet, deciding that. Or if you really want a "safe country", then at least build in a guarantee that if the person is going back to that country he or she may enjoy status or he or she may have access to the refugee system. Now we have no objections if a person is in a refugee system processing in Germany and then comes here. We'd say, "look, you started in Germany, go back to Germany, finish it there, so we could help someone who doesn't have that."

AZ: Would you consider a definition of "safe country"?

SM: I'd like to get away from the whole thing of the "safe country". I think it's got a bad name. The Tories made it a bad name. I'd like to get a system whereby if people enjoy refugee status already once, and they apply here, I'd say no, because there are too many people who don't have a home that we should give rather than spending time finding a second home. People who are going in a refugee system in Europe or somewhere else and then come here at the same time, that is a no-no as well. They go back to their country, they finish their process there. If a person who comes from the States and stops overnight or a couple of days and comes here, then the only way we should send that person back to the United States is if that person has an eligibility to apply there. If he doesn't then we might as well take a look at it here. So those are the concepts that I am talking about and I'd like to get away from the "safe country" concept and define it by another set of words because I think it's got a meaning which I think is doomed in a lot of constituencies.

AZ: If you win the election, how long do you thing it will take you to put through these refugee bills?

SM: That's what I am looking at. Is it better to try to amend a law that is already passed or start a new one to go through the second reading, third reading, committee, Senate. I would hope that if it's possible to amend with the sake of time in mind, then we would amend. And I would hope that any Minister of Immigration would make this priority number one. I am hoping that within the first five to six months of a new administration we get that bill and the amendments through the house, through the Senate, and get it working. At the same time in those first six months, action on the refugee backlog, action fast, action quick, so by the time, hopefully, that the new system is in place, we will have begun to get the backlog in order, so it doesn't conflict with the new system.

\section{... drop the pre- screening stage, allow people to make one oral effective and fair hearing and then make a determination.}

\footnotetext{
AZ: What do you think about the appointments to the Immigration and Refugee Board?

SM: A number of them obviously have Tory connections. I would hope that what we have here on the refugee side, is people who have some expertise in refugee matters because that's important. If a person knows the business, then the business of processing is going to be speedier. You are much more prone to know what is good, bad, what is legitimate, what is illegitimate, and people who can distinguish between what is a refugee
}

and what is an immigrant. So I would be satisfied if the people who have been selected have a solid foundation because that would determine the type and the quality of decisions and the speed of decisions. And those two factors are very crucial.

\section{AZ: Any final comments?}

SM: My final comment would be to say this. Liberals understand better than the present government the importance of immigration and refugee policy. Liberals, I think, recognize that immigration has to be a building block and a corner stone to nation building. Why do I say that? Because I belive that we recognize that here we have a large country with a relatively small population base. We have a rich country. We have a dwindling birth rate. We have an aging population. We have fifty thousand people leaving this country every single year and not returning. We have needs for professionals that our schools are not putting out quick enough for our economy. Therefore one answer to those problems is immigration. It is not the only answer, but it clearly is one answer, because nation-building doesn't stop in 1990 or in one year or two years. It keeps going. And if we continue at this pace, by the year 2020 experts believe that we are going to be going backwards in population. That's going to have a detrimental effect on the work place, on our pension system, on our social service system and on our lifestyle as Canadians. So, let's not wait until 2020 to jack up the immigration to 600,000 to keep pace. Let's begin to plan now. Let's have some foresight, let's have some vision of where this country has to go and begin to put in place the stages now, and, at the same time, let's keep in mind that we've got to tell Canadians what we are doing in a positive way. Do some educating. Let's get rid of those stereotypes so that Canadians can be allowed, with government's help, to be progressive. The example of the 1980s with the Vietnamese boat people was a clear example that when governments take leadership, when Canadians are told about the problem in an effective way, they will respond, as we did in that clear example, and that should be the example that should lead the way, and that we should have the best intentions to lead rather than following our worst fears. And that's something I think this government cannot be proud of in the way they've handled the immigration and the refugee situation. 


\section{Dan Heap}

Alex Zisman: What are your views on
Bills C-84 and C-55?
Dan Heap: If we can we will repeal the whole bill and will start with a new bill. However, since that might take time to do, in the short term we would concentrate on two things. If we had control of the Cabinet we would simply remove any countries' names that might be on the list of so called "safe countries", so that there would be no place to which a person could be sent on grounds that he could have made a claim there as a "safe country". We would also ensure that the Cabinet instructed the Immigration Commission not to return people compulsorily to countries that we would list as being in danger, like the old B-1 list, that being places of danger, without having their refugee claim examined. In other words we would administratively cancel the most offensive part of Bill C-55 which is the pre-screening. We would also administratively change the procedures of the Refugee Board so there would be a sort of review panel of the most experienced or senior Board Members who would review negative decisions to make sure both that they are not clearly faulty and that there was a uniformed standard of judgement across the country, since there would be many different locations in which these cases will be judged. Those are the two main changes that we would make administratively and as quickly as possible, very quickly after a new government, if we have the power to do it. Namely we would proceed to write completely new amendments to the Immigration Act to replace Bill C-55 and Bill C-84.

AZ: What do you plan to do about the notion of "safe country"?

DH: According to a study done by a lawyer on staff with the Standing Committee on Labour, Employment and Immigration - she is a library researcher of the House of Commons - there is no agreed concept of "safe country". So far as we can find out, the present government has been completely unable to arrive at an agreement with any other of these so called "safe countries" for sending people back there. Therefore, for both those reasons we simply would abolish the use of those words because there never has been an agreed definition.

AZ: How would you cope with the bureaucratic problem that would entail deal-

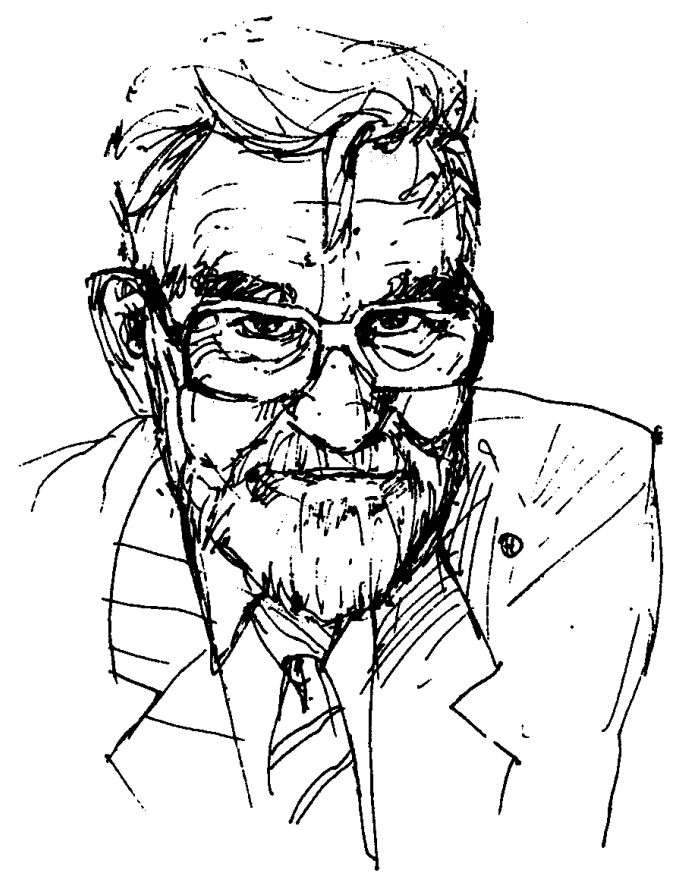

Dan Heap: "There is no agreed concept of 'safe country'."

ing not only with the new refugee claims but with the backlog that is now well over 60,000 ?

DH: We will have to follow Rabbi Plaut's suggestion that he made when it was only a quarter of that, in other words a special procedure for the backlog. That would not be part of the new procedure for new arrivals. It would be something like what has been called the administrative review. It could be more fairly done. For example, the existing administrative review was unfair towands women from Third World countries, who in many cases were supporting their children here, but, because they earned less than $\$ 20,000$, were judged to be unfit to support their children here, and were refused landed status for that reason. That is quite unreasonable, unnecessary and unfair. But the new procedure would again be much like the one that the Standing Committee recommended three years ago. As soon as a person arrives, make an appointment for him with the Refugee Board, who will then examine his or her claim fully in an oral hearing, as required by the Supreme
Court, and decide whether he or she is or is not a refugee, and then and only then would immigration examinations of his or her case begin. In other words the human rights issue of refugee status must come before the administrative issue of immigration. The basic trouble with the present system is that those things are put on the wrong sequence, the wrong order. If that were done, it can be done in about three months normally, and in almost all cases six months maximum. Very few cases would have to go as far as six months. This is what I believe after our discussions with the senior officials of Immigration. And we would thereby make these scams impossible - like the Portuguese scam, the Brazilian scam, the Turkish scam and the Panamanian scam, because there would be no hope for a person staying long enough in Canada to earn enough money to pay back what he paid to the scam operator, let alone anything extra. So that would mean there would be no unreasonable build-up in the future, unless the government made the same mistake as it made during the past ten years of understaffing and underfunding the refugee process. 
AZ: How would you deal with ships trying to smuggle refugees?

DH: We would certainly not turn the ship away in those cases because we do not know what would happen to the people in the ship. We would allow the ship to land or we would even send a naval escort to compel the ship to come into port and we would examine the people on it and we would, if necessary, seize the ship and take legal action against the captain of the ship. This is now part of Bill C-84 that we in the opposition recommended. And it was adopted. That they should be compelled to come to port so that they could be examined. There is no value in turning the ship away because that lets the possible offender go free, but it endangers the lives of possibly innocent people.

AZ: What do you think of the new Immigration and Refugee Board?

DH: By the Government's statement of the qualifications, many of them appear to have no qualifications whatever in refugee matters. And I know of certain people who are qualified in refugee matters who were not asked to be part of the Board, including, I understand, some people who have been on the present Refugee Status Advisory Committee or the Immigration Appeal Board. Clearly some of these people were personal friends or supporters of the Tory government and the appointment appears to be a financial reward to them for their loyal support. I think that is extremely bad because it means that the job of examining the refugees will not be well done. They have put less competent people in there for the sake of money.

I cannot comment on their claim that 40 percent of their appointees are of visible minorities, I haven't scen the people, but I don't believe that that is the issue. The question is, are they people who have shown some competence and understanding in identifying refugees or in assisting refugees? The question of their colour, or the question of their ethnic origin is by itself irrelevant.

\section{AZ: Any final comments?}

DH: The Conservative legislation extends a policy that has been developed administratively of favouring the wrong kind of people to bring in on refugee grounds. That is to say they select them primarily for their immigration qualities, their benefit to Canada, rather than for their need as refugees, which is our obligation under the law.

\section{Barbara McDougall}

Alex Zisman: Many refugee adoocates heoe expresed concern about the implications of Bills C-84 and C-55, which are seen as deterrence measures somehow prompted by incidents such as the arrioal of Latin American refugee claimants from the U.S. or the boatload of Tamils. What was the real purpose of these bills?

Barbara McDougall: The bills have three purposes. There were not triggered by a particular group in a particular place. Clearly the current legislation is not working. I am sure that everyone would agree with that. So that we had to look at the situation on our borders around refugee claimants who were arriving in Canada unannounced, wherever they came from. This had nothing to do with Central Americans or South Americans.

The first purpose is to ensure a system where genuine refugees will continue to be welcomed in Canada and where we can move them into a system and get them landed as rapidly as possible.

The second is to ensure that false claimants who arrive are turned around faster and do not establish roots here. There is nothing wrong with people coming from offshore but that is an immigration process and we expect people to go through the same immigration process if they are not genuine.

The third objective is to try and get rid of the scams, the people who take advantage of economic migrants who are feeling a lack or opportunity, or who are moving around the world for whatever reason, and who give people all their savings in order to come to Canada on a boat or plane to take advantage of the system here. And people who traffic in human flesh that way are going to feel the full weight of the law. Those are the objectives of the two bills.

AZ:What is the definition of a "safe country" and what procedures will be set up to define protection of genuine refugees?

BMcD: First of all we will not send people back to any country where they would be put in orbit or where they would automatically be sent back to their country of origin. We would only select safe thind countries on the basis of their commitment to the UN Convention and provided they have a refugee process of their own that people can go through and get a hearing in. The point is there are 12 million refugees in the world. It is not up to Canada alone to solve that problem. There are other countries who must be involved and that have to take part in solving these problems. We are consulting with organizations and academics around what those countries should be before we determine the final list. I think that it will probably be a shorter list than people expect and there may be countries where we would send back some people but not others.

\section{... we will not send people back to any country where they would be put in orbit or where they would automatically be sent back to their country of origin.}

AZ: You just mentioned that they would not be sent to countries where they would be put in orbit. I believe the current legislation makes that a real possibility. In view of Amnesty International's proposal to add an amendment to prevent this possibility, how are you going to proceed with that amendment and how is it going to be added to the actual bill?

BMCD: Well, I have no plans at this moment to amend the bills. I have already amended them to some extent to meet people's concerns, and that's what the legislative process is for $-I$ am quite happy to do that. But I have no intention at this point of amending the bills again. I have a recent letter from Amnesty, which I have not really gone through with in any detail, that touches on this among other things. 
AZ: What refugee adroocates find is that Canada traditionally has been concerned with deciding who is going to come to this country, be it immigrants or refugees. They view this bill as a deterrent to refugees who decide on their own to come to Canada.

BMcD: No, refugee claimants; there is a difference, OK? If refugees showup on our shore and they are genuine refugees, they are welcome to stay. And a process has been established in such a way that they will stay. Refugee claimants are different than refugees. Now you know that, and everyone involved in this business knows that.

AZ: Yes, but what I am saying is that the measures contemplated in this legislation are measures which will serve as deterrents not only to fake refugees but to refugees in general...

BMcD: I don't think so ...

AZ: ... because they will create more and more abstacles before their arrioal to Canada.

BMcD: No, it won't create any more obstacles for genuine refugees.

AZ: Well, that is open to interpretation. There is another issue. It would appear that all these measures will affect a very small percentage of the refugees that arrive. There is an article in the last issue of Refuge where Howard Adelman argues that a maximum of $10 \%$ of refugee claimants will be refused entry to the refugee determination process. The legislation dedicates a lot of time and effort to implement a procedure that will probably only affect a very small percentage of the people that are coming in. The same results could have been achieced by following the direction of the Plaut Report, for example.

BMcD: Well, the Plaut Report, contrary to popular opinion, does not call for universal access, and they have some standards in it, too. They are defined a little differently, but on balance they would have accomplished the same thing. And we chose this route, as opposed to that route, but it is not as different as all that.

AZ: The effectioeness of this legislation will depend a great deal on proper documentation. For example, airlines and transport carriers are being penalized for bringing people who haven't got proper documentation. But if this documentation disappears at one stage, the whole process again will be stuck in the middle, because basically what the government has done is tackle a specific problem, a specific series of violations of the arrioal procedure to prevent them from being repeated. And the measures that have been taken will stop these specific ways that have been used by fake refugees and other dubious openators, but this in no way preoents these very same people

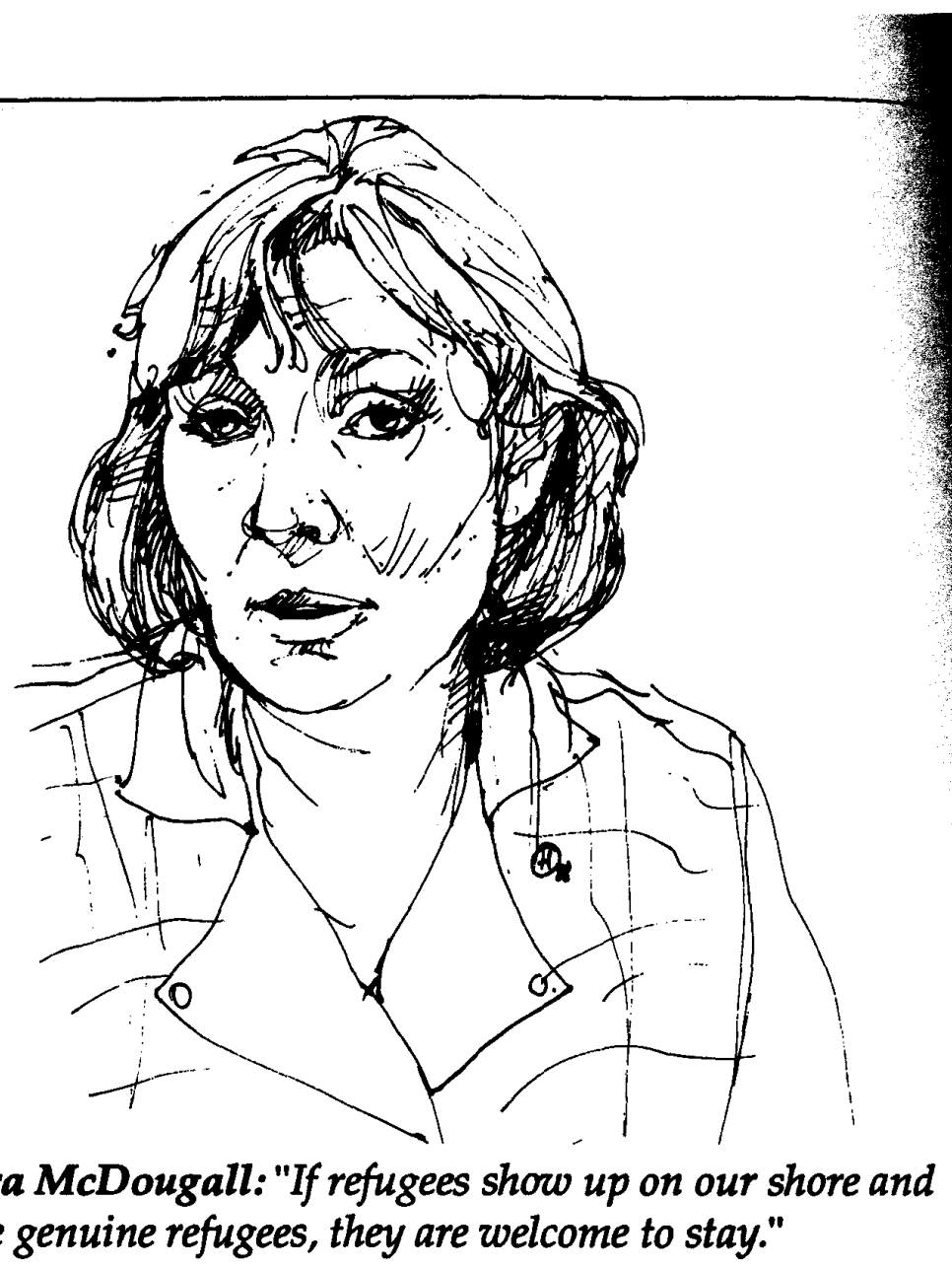

from utilizing other illegal ways to come in that would still circumoent the present legislation. A great deal depends on the specific documentation carried by these people.

BMcD: Well, it will be harder for them to circumvent the new system than it was for them to circumvent the old system. And everything that we have done we have done with the perspective of continuing to welcome genuine refugees and turning the others around fast, and encouraging them to come as immigrants. If they want to apply as immigrants that's fine, but then they can come as immigrants along with other people who come as immigrants.

AZ: The other concern of the refugee lobby is that there are going to be Charter challenges that are going to bog down the whole process again and make it eoen more unworkable than the other one.

BMcD: Well, if there are challenges there are challenges. There are Charter challenges every day and sometimes they go one way and sometimes they go another way. The Liberals have said when they brought in the Charter that they would make all legislation consistent with the Charter. Well, they didn't. Unemployment insurance being the perfect example. We have a lot of cases on unemployment insurance. And we do not quarrel with the findings because we know that much of our legislation which we are trying to work through and make consistent isn't. If there is a Charter challenge we will deal with it when it arises and we will see what the courts do. We have made every effort to ensure that the legislation is consistent with the Charter. But that does not mean that it won't be challenged and it also does not mean that the challenge will win. I mean, if it wins, it wins.

AZ: When I interoiewed Sergio Marchi and Dan Heap, one of the things about which they showed concern was the way the legislation will deal with refugee smugglers, and particularly with see coptains who avoid facing fines or imprisonment when their ships are turned back, while the fate of the refugee claimants they are bringing remains in limbo. 
BMcD: The provision about the ships is sunsetted, and as soon as the new legislation is operative there is a clock ticking and that will come to an end. Secondly, it also provides for the fact that boats will be escorted in. And there are things having to do with seaworthiness, food supplies and all those things. We are not going to turn boats around into the North Atlantic in January and have people run into an iceberg. There are safeguards in the legislation and also the whole thing about the boats dies once l've got a system that is working. Then people who arrive by boat are going to be treated as anyone else, whether they arrive by plane, on foot, by bus, whatever. What we are trying to do is discourage unscrupulous captains and

\section{We are not going to turn boats around into the North Atlantic in January and have people run into an iceberg.}

profiteering refugee entrepreneurs in Europe from sending people off in boats that are unseaworthy and crowded, and in conditions that are bare survival, to arrive in our shores. That is exactly the kind of trading in human flesh that would not tolerate. So that that provision will be sunsetted, is sunsetted now, and while it is in place, all the provisions around seaworthiness and supplies, and all that, remains.

AZ: You inherited a backlog that kept on growing and growing. How are you going to handle this backlog?

BMcD: I am going to go to Cabinet with a proposal. We will have some discussion about it. We have not decided yet, except there will be no amnesty. I have said that a number of times. But beyond that there are a couple of ways we could deal with it, one is an administrative review, similar to the last time, with

Continued on page 10

\section{Amnesty International: A Letter to the Minister}

Amnesty International works for the release of prisoners of conscience, being persons who have been arbitrarily detained, tortured or executed for the non-violent expression of their beliefs, and is opposed to torture and the death penalty in all circumstances. Accordingly, Amnesty International is opposed to a country sending a person to another country where that person faces the risk of arbitrary detention, torture or execution.

In the context of asylum and asylum pro cedures, Amnesty International is of the view that no refugee claimant should be removed from a country before a fair hearing on the merits of his/her claim has taken place unles such claimant has the right to be admitted to a third country and has access to a refugee determination procedure which includes a fair hearing on the merits. As well, the said third country should normally be a party to the 1951 United Nations Convention relating to the Status of Refugees and must respect, in fact, the spirit of the Convention. Furthermore, before a country removes a refugee claimant to a safe third country, Amnesty International is of the view that the claimant should be given the opportunity to explain why the safe thind country would not be safe for him or her.

Amnesty International has received continuous reports over the years that people who are perceived to be opponents of the government in countries in Central America, and in particular El Salvador and Guatemala, have "disappeared", been tortured or been executed by "death squads". Amnesty International believes that the "death squads" are comprised of regular police and military agents, operating in plain clothes but under superior orders as an intrinsic part of the security apparatus in these countries. Many of those who have been executed in this way have previously received death threats. Such threats, including threats on the telephone, are quite common. Many people who have received death threats flee to seek asylum in other countries.

Amnesty International's concern for asylum seekers from these countries in the United States is heightened when the State Department and judicial authorities often require written corroboration that asylum seekers have received such death threats in order to be considered credible. Most "death squads" do not leave written documentation to confirm that a threat has been made. In Amnesty International's view, to require refugee claimants to produce written corroboration of death threats in order to be considered credible is a standard of proof that is unrealistic and, therefore, unfair.

There have been numerous cases where it appears that American authorities have regarded asylum seekers from Central America as economic migrants when many of them are bona fide asylum seekers, including asylum seekers who are at risk of arbitrary detention, "disappearance", torture or execution in the countries from where they have come. Moreover, this assumption on the part of the authorities has led to instances where Central Americans have been strongly discouraged from applying for asylum, or even coerced into accepting voluntary departure from the United States. Such practices as they affect Salvadoreans in particular were highlighted in the recent U.S. Federal Court decision of Oranties v. Meese, which describes how many Salvadoreans who lack documentation are held in detention centres in remote areas without adequate access to telephones, writing materials or other means to retain lawyers who can help them in pursuing their asylum clains.

After consulting the Research Department at the International Secretariat of Amnesty International, in London, England, and after consulting the U.S. Section of Amnesty International, the Canadian Section has concluded the following:

1. there are instances where Central Americans have been strongly discouraged by American authorities from applying for asylum and even coerced into accepting voluntary departure from the United States;

2. many asylum seekers from Central America are detained, which may impede their chances to pursue effectively their claims for asylum by being hindered from contacting lawyers who can assist them; and

3. the high standard of proof often required from asylum seekers from Central America in order to prove their credibility is unreasonable.

Therefore, the Canadian Section of Amnesty International considers that the asylum procedures and practices in the United States as they relate to Central Americans are not sufficient to ensure the protection of bona fide asylum seekers from these countries.

Accordingly, it is the view of the Canadian Section that if the Canadian Covernment were to send Central American asylum seekers to the United States to have their refugee claims determined there, this would increase the risk that Central Americans might be returned against their will to a country where they risk being arbitrarily detained, made to disappear, tortured or executed.

Yours truly,

Michael S. Schelew 
those criteria or different criteria. The other is to add to the resources of the Immigration and Refugee Board on a temporary basis and have a kind of parallel stream dealing with the backlog, and, you know, I would have to go to Cabinet before I am able to say how we are we going to do it.

AZ: So at this time you don't have a specific time frame to determine how long you will take.

BMcD: No, I'd hoped to get it in before the election, but there just wasn't time.

AZ: Some critics have indicated that the patronage appointments at the Immigration and Refugee Board can indeed be seen as a sort of plum ...

BMcD: Like, this is a whole pile of crap. We have a Refugee and Immigration Board which has on it a woman named Dorothy Davey, who is Keith Davey's wife. When she was appointed to this Board she was the wife of a Liberal senator. She has done a very good job and she is still on the Board. And just because somebody has been a Conservative doesn't mean they don't have a contribution to make. This Boand, every single person on this Board, whatever their political background - and many of them don't have a political background at all - either have some experience with refugees, some experience with multiculturalism and the academic field, or something that gives them a contribution to make. They are also going through the best training of any board in the world, and the UN says that, too [Several lawyers and law professors have indeed praised the training, but when we asked the UNHCR to confirm Barbara McDougall's claim, an official at the UNHCR office in Ottazwa said he was not awoare of any concrete or specific comments of this nature (editor's note)] So I think that the quality of the Boand is absolutely above reproach. And to suggest that because somebody is related to somebody's father and therefore is no good, is an insult.

AZ: I didn't finish the question. When Dan Heap was referring to this thing, he said that what mattered was not the origin or background of these people but their qualifications. And he wasn't at all sure that most of these people were adequately qualified. Although many of them had worked in the previous board, they were again appointed to that board without any prior experience, so their experience...

BMcD: But they have experience now, don't they?

\section{AZ: Very limited.}

BMcD: Well, how do you think people got there before? There were people on the board before that had no experience, but they were trained and they developed the experience. It is no different except that the experience now of the new appointments is better. They were also the first ones to say that we should reappoint the people on the existing board. And they said "you cannot fire all these people", which we have no intention of doing. We looked at the quality of the existing board and we added to it.

\section{... the quality of the Board is absolutely above reproach.}

\section{AZ: But for example joe Stern wass left out. And Susan Davis ...}

BMCD: That wasn't the board, they were on RSAC. And many of these people are located in Ottawa. There is no great demand for refugee people in Ottawa. The demand is in Toronto, in Montreal, in Vancouver, in Halifax and other places. So there were some people who were offered an opportunity to move and turned it down. They were not all offered that opportunity, but we did find people in the places were the need is and even then a few who went through the list would tell that it is all right.

\section{... who knows what's going to happen? I don't know.}

AZ: People have different perspectives on the various participants. But in any case Gordon Fairweather expressed concern himself that he will not be able to cope with the issues arising from the backlog. 